\title{
A Novel Compact CPW- Fed Antenna for ULTRA WIDEBAND Applications
}

\author{
S. kareemulla ${ }^{* 1}$, Prabhakar S. Manage ${ }^{* 1}$ N. Gunavathi ${ }^{* 2}$ \\ ${ }^{1,2}$ Assistant professor, Department of Electronics and Communication Engineering \\ ${ }^{1}$ MVJ college of Engineering, Channasandhra,Bangalore, \\ ${ }^{2}$ National Institute of Technology, Tiruchirappalli, Tamilnadu, INDIA.
}

\begin{abstract}
This paper presents the analysis of compact and simple, CPW-fed antenna with 10dB return loss (VSWR <2) band (3.08 10.6 GHz) band for ULTRA WIDEBAND applications. The antenna consists of ground plane, rectangular slot and polyhedron-shaped exciting stub. This antenna is designed on a substrate with dielectric constant $\varepsilon_{r}=4.4$ and with size $24 \mathrm{~mm} \times 19 \mathrm{mmx} 1.6 \mathrm{~mm}$. The fundamental parameters of the antenna such as $2 D$ radiation patterns, VSWR, return loss, gain and bandwidth are obtained and all meets of the acceptable antenna standards. The simulation results of this antenna are analyzed by using Method of Moment (MOM) from ZELAND IE3D version 12.0 software.
\end{abstract}

Key words - CPW- fed antenna, Polyhedron shape, Compact size, UWB applications.

\section{Introduction}

RECENTLY, with the rapid development of wireless communication systems for local access networks including Personal Digital Assistants (PDA), portable PCs, and Bluetooth, the need for low profile and compact antenna has been on the rise. The demand was increased day by day in wireless communication, especially for the ULTRA WIDEBAND Applications. Small and effective wireless communication systems are always preferred. Low profile antenna has therefore been a very hot research topic in antenna engineering. UWB(Ultra-Wide Band0 techniques have been paid the most attention for many advantages, such as higher data rates, immunity to multipath cancellation, increased communications operational security and low interference to legacy systems[1]. However, the UWB communication systems use the $3.1-10.6 \mathrm{GHz}$ frequency band, which includes the IEEE $802.11 \mathrm{a}$ defines three frequency bands that can be used. The first band extends $5.15 \mathrm{GHz}$ to $5.25 \mathrm{GHz}$, the second from $5.25 \mathrm{GHz}$ to $5.35 \mathrm{GHz}$ and the third from $5.725 \mathrm{GHz}$ to $5.825 \mathrm{GHz}$. On the other hand, the HIPERLAN/2 specifies two bands: from $5.15 \mathrm{GHz}$ to $5.35 \mathrm{GHz}$ and from $5.470 \mathrm{GHz}$ to $5.725 \mathrm{GHz}$ [2-3]. Therefore, UWB communication systems may generate interference with IEEE802.11a. To overcome electromagnetic interference between UWB systems and WLAN systems, various UWB antennas with notch function have been developed for UWB communication systems [4]. The proposed antenna in this paper designed with compact rectangular slot and polyhedron shaped existing stub and cross patch like feeding structure at the anterior portion of the feed. The simulation software used for this analysis is ZELAND IE3D version 12.

Now a day's CPW FED antennas have many attractive features like low radiation loss, less dispersion, easy integration for monolithic integrated circuits, so these types of antennas have recently become more and more attractive. In addition, the CPW feed is particularly suitable for millimeter wave applications because of reduced surface wave excitation in electrically thick substrates. The proposed antenna has the advantage of compact size, which makes it attractive for mobile devices.

\section{Antenna Structure And Design}

The scheme of the proposed small novel compact CPW-fed antenna for $(3.1-10.6 \mathrm{GHz})$ Ultra Wideband applications is shown in Fig.1. Its simple structure is based on a one-layer FR4 dielectric substrate only, which has thickness as $\mathrm{h}=1.6 \mathrm{~mm}$ and permittivity of $\varepsilon_{r}=4.4$. Here the thickness of the substrate is thin and hence we can say that the cost of the substrate and weight of the antenna are less. The antenna consists of two layers, which are the substrate layer and the radiating layer. The ground plane of the antenna is located on the same side of the CPW-feed and radiating layer. 


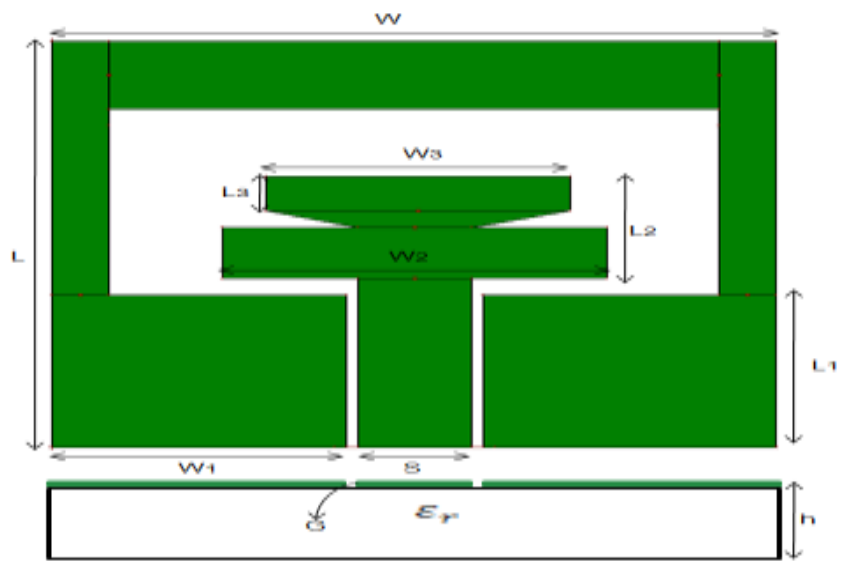

Fig. 1 Layout of the proposed antenna

The radiation portion contains one rectangular slot and Polyhedron shaped existing stub placed from the CPWfed. The fundamental parameters of the antenna such as return loss, VSWR, gain, directivity and polarization are obtained. All meets the acceptable antenna standards. Simulation tool, based on the method of moments (MOM)-ZELAND IE3D version 12.0 has been used to analyze and optimize the antenna. The designed parameters are shown in Table I.

TABLE I. PARAMATERS OF THE PROPOSED ANTENNA

\begin{tabular}{|c|c|c|c|}
\hline Parameters & $\begin{array}{c}\text { Value } \\
\text { (in mm) }\end{array}$ & Parameters & $\begin{array}{c}\text { Value } \\
\text { (in mm) }\end{array}$ \\
\hline L & 24 & L2 & 5 \\
\hline W & 19 & L3 & 1 \\
\hline W1 & 8.2 & L4 & 2 \\
\hline W2 & 11 & h & 1.6 \\
\hline W3 & 7 & G & 0.3 \\
\hline L1 & 9 & S & 3 \\
\hline
\end{tabular}

\section{Simulation Results}

A prototype of the novel compact CPW-fed antenna for $3.36 \mathrm{GHz}$ and $5.58 \mathrm{GHz}$ band has been simulated. The simulated return loss curve of proposed antenna covers the frequency range from $3.08 \mathrm{GHz}$ to $12 \mathrm{GHz}$ with return loss less than $-10 \mathrm{~dB}$ and VSWR less than 2.The Return loss achieved is absolutely good about $-20.6 \mathrm{~dB}$ and $-27 \mathrm{~dB}$ is observed at $3.36 \mathrm{GHz}$ and $5.58 \mathrm{GHz}$ and VSWR of the antenna is less than 2 as per the required norm in the frequency band as shown in figures (2) and (3).

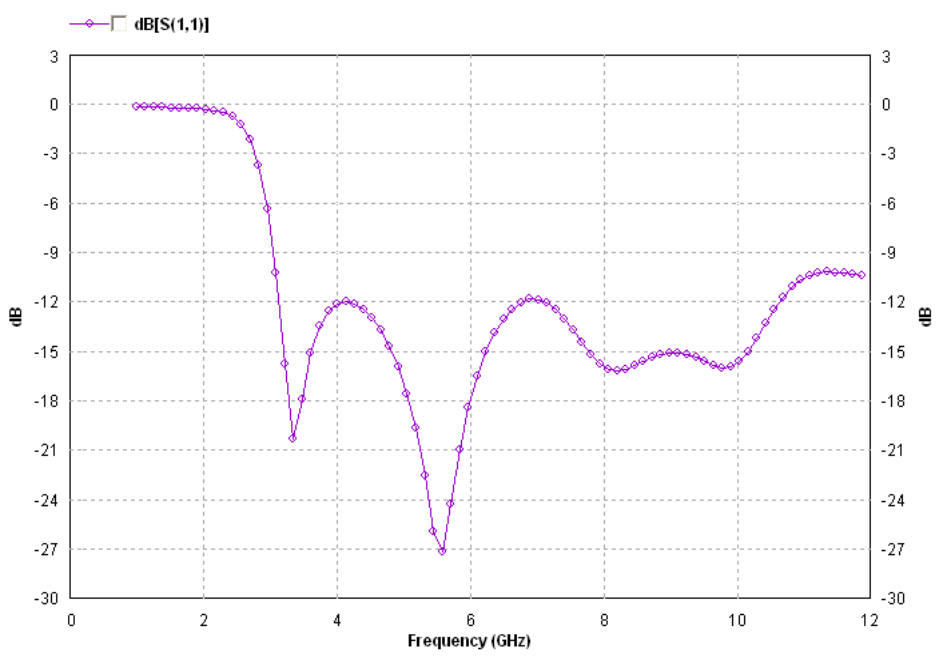

Figure 2: Return loss of the antenna 


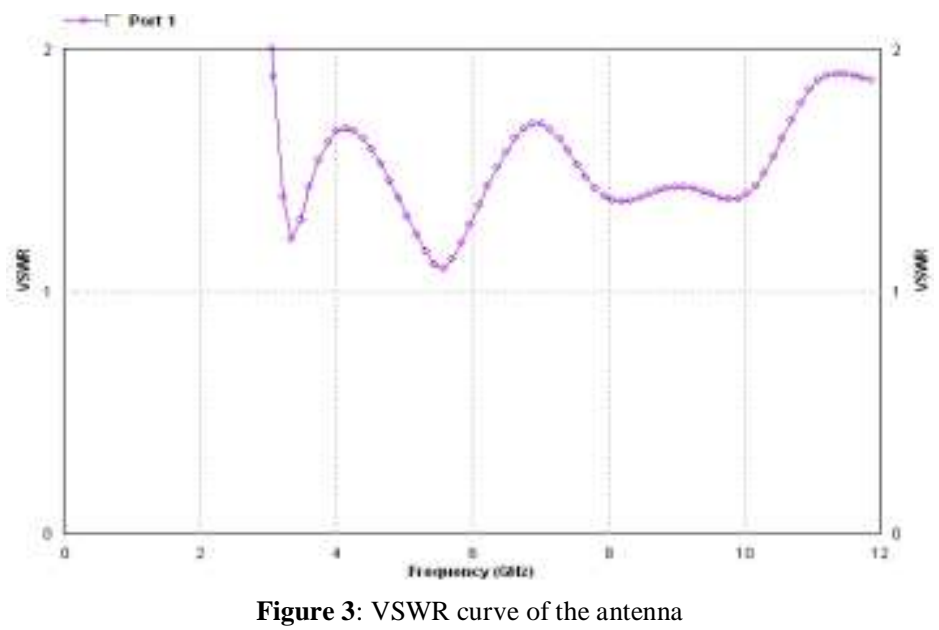

The Figures shows the simulated radiation patterns with Elevation and azimuthal at a resonant frequency by using ZELAND IE3D software. The simulated radiation patterns of the antenna is Omni directional which means that radiating power is uniform in one plane with a directional pattern in a perpendicular plane. For this proposed antenna E-plane (XZ-plane) and H-plane (YZ-plane) for $3.36 \mathrm{GHz}$ and $5.58 \mathrm{GHz}$ are shown in Figure $4 \& 5$ and Figure $6 \& 7$. The patterns and other curves are obtained at the time of simulation.

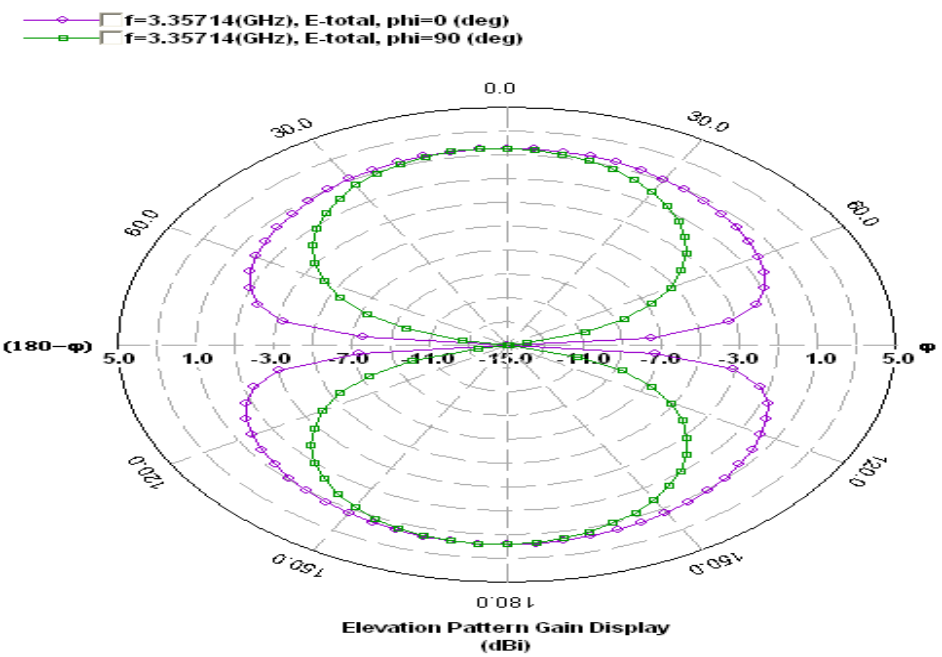

Figure 4: E-Plane Radiation pattern of the proposed antenna at $3.36 \mathrm{GHz}$.

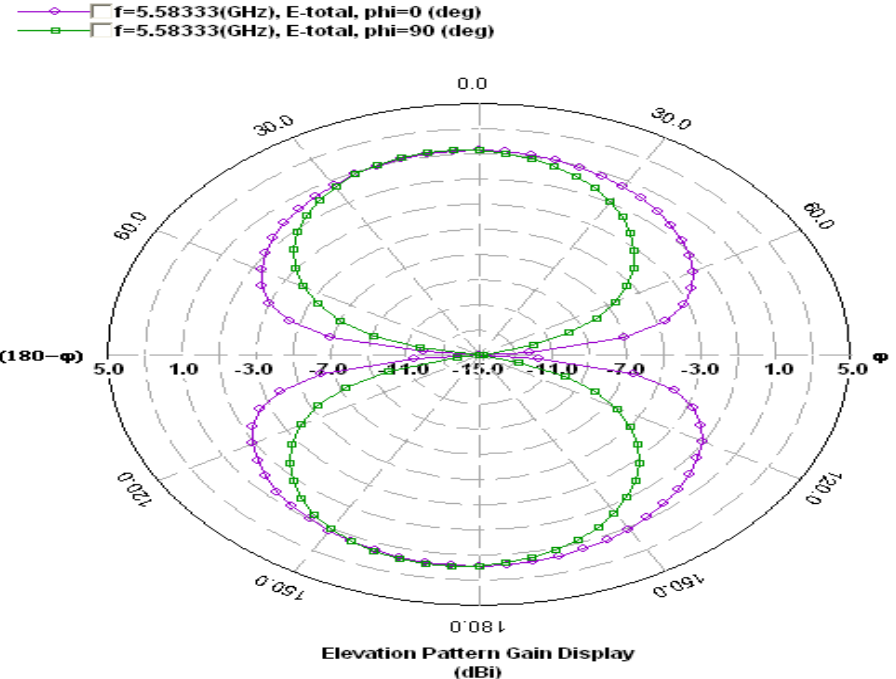

Figure 5: E-Plane Radiation pattern of the proposed antenna at $5.58 \mathrm{GHz}$. 


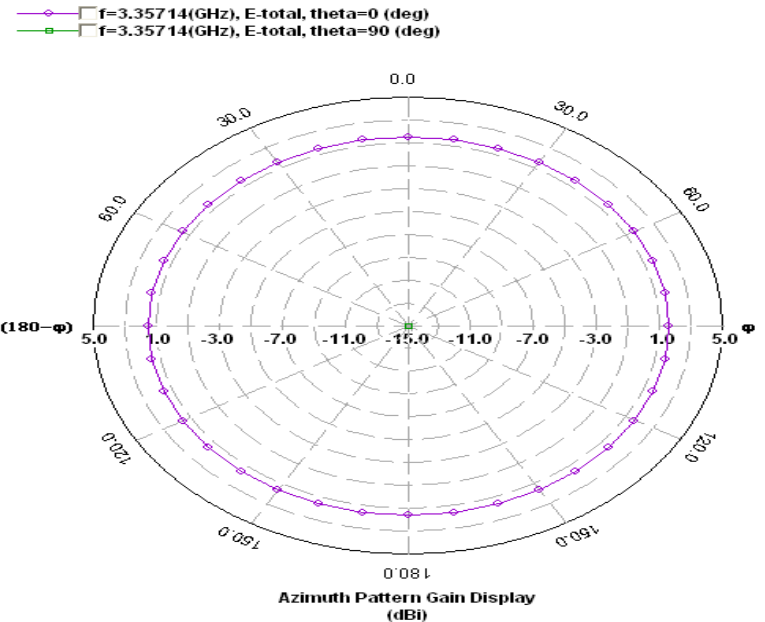

Figure 6: H-Plane Radiation pattern of the proposed antenna at $3.36 \mathrm{GHz}$

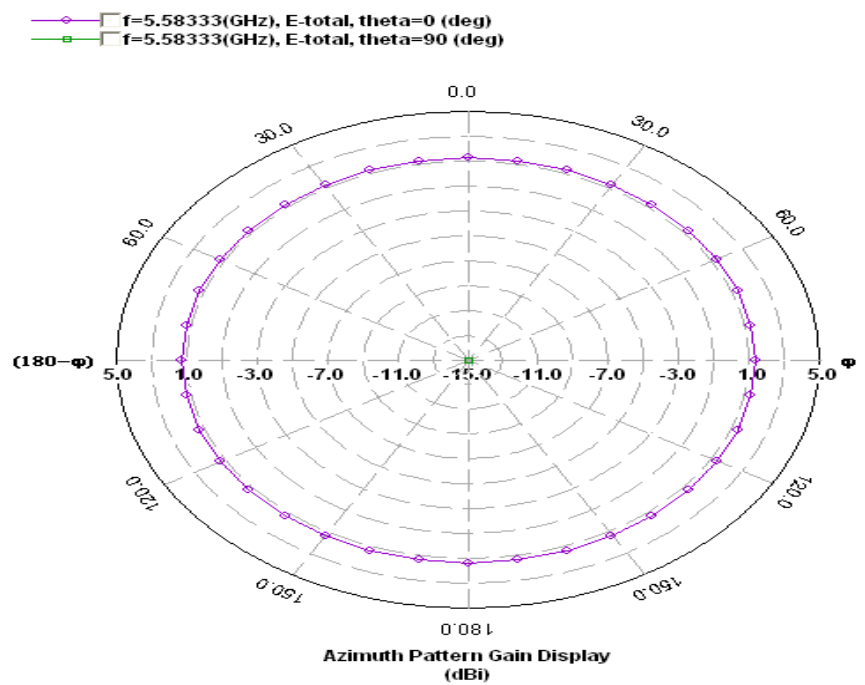

Figure 7: H-Plane Radiation pattern of the proposed antenna at $5.58 \mathrm{GHz}$.

\section{Effect of W2:}

Figure 7 plots the simulated return loss curves with different W2 when L4 is kept constant value. By varying the aperture dimensions it is observed (Figure 7) that the resonant frequencies slightly varied at a cost of increasing voltage standing wave ratio and return loss of the antenna. It is noticed that return loss and gain are maximum for $\mathrm{W} 2=8 \mathrm{~mm}$ as shown in TABLE II.

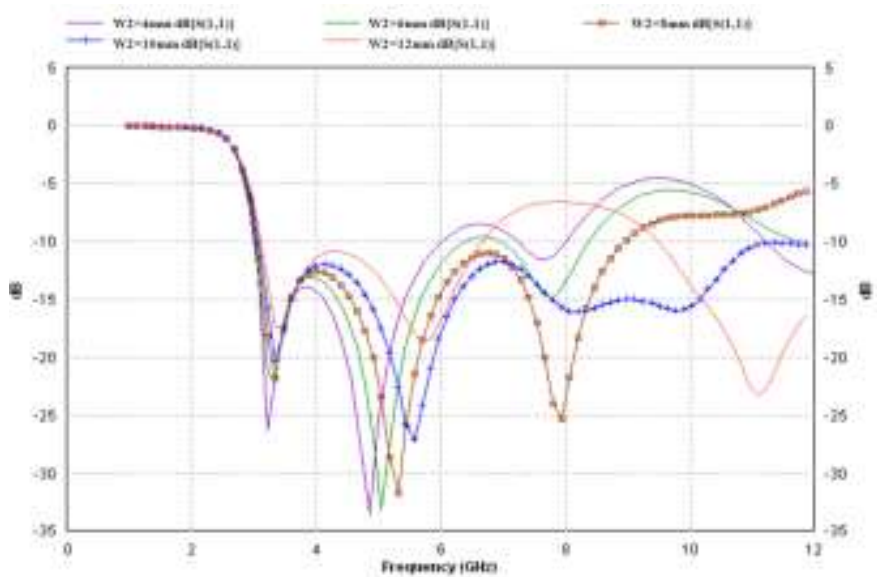

Figure 7: Simulated Return loss with different values of W2 
TABLE II

\begin{tabular}{|c|c|c|c|c|}
\hline $\begin{array}{c}\text { W2 } \\
(\mathrm{mm})\end{array}$ & $\begin{array}{c}\text { Resonance } \\
\text { frequency } \\
(\mathrm{GHz})\end{array}$ & $\begin{array}{c}\text { Return loss } \\
(\mathrm{dB})\end{array}$ & VSWR & $\begin{array}{c}\text { Gain } \\
(\mathrm{dBi})\end{array}$ \\
\hline 4 & 3.22 & -25.52 & 1.13 & 1.70 \\
& 4.86 & -33.36 & 1.05 & 1.53 \\
\hline 6 & 3.34 & -22.12 & 1.17 & 1.75 \\
& 5.06 & -33.21 & 1.04 & 1.82 \\
\hline 8 & 3.36 & -21.72 & 1.17 & 1.76 \\
& 5.3 & -31.24 & 1.05 & 1.94 \\
\hline 10 & 3.36 & -20.00 & 1.21 & 1.75 \\
& 5.58 & -27.13 & 1.09 & 1.85 \\
\hline 12 & 3.36 & -17.47 & 1.3 & 1.72 \\
& 5.72 & -18.63 & 1.26 & 1.75 \\
\hline
\end{tabular}

\section{Effect of W3:}

Figure 8 plots the simulated return loss curves with different W3 and L3 is Kept constant. By varying the aperture dimensions it is observed (Figure 8) that the resonant frequencies slightly varied at a cost of increasing voltage standing wave ratio and return loss of the antenna It is noticed that return loss and gain are maximum for $\mathrm{W} 3=10 \mathrm{~mm}$ as shown in TABLE III.

TABLE III

\begin{tabular}{|c|c|c|c|c|}
\hline $\begin{array}{c}\text { W3 } \\
(\mathrm{mm})\end{array}$ & $\begin{array}{c}\text { Resonant } \\
\text { frequency } \\
(\mathrm{GHz})\end{array}$ & $\begin{array}{c}\text { Return } \\
\text { loss(dB) }\end{array}$ & VSWR & $\begin{array}{c}\text { Gain } \\
(\mathrm{dBi})\end{array}$ \\
\hline \multirow{2}{*}{4} & 3.36 & -13.29 & 1.54 & 1.59 \\
& 5.86 & -19.89 & 1.22 & 1.8 \\
\hline \multirow{2}{*}{6} & 3.36 & -15.99 & 1.37 & 1.68 \\
& 5.62 & -23.10 & 1.15 & 1.87 \\
\hline \multirow{2}{*}{8} & 3.36 & -20.87 & 1.2 & 1.75 \\
& 5.46 & -29.84 & 1.07 & 1.9 \\
\hline \multirow{2}{*}{10} & 3.38 & -35.27 & 1.04 & 1.78 \\
& 5.16 & -35.10 & 1.03 & 1.95 \\
\hline \multirow{2}{*}{12} & 3.52 & -28.46 & 1.07 & 2.88 \\
& 4.7 & -24.75 & 1.12 & 1.61 \\
\hline
\end{tabular}

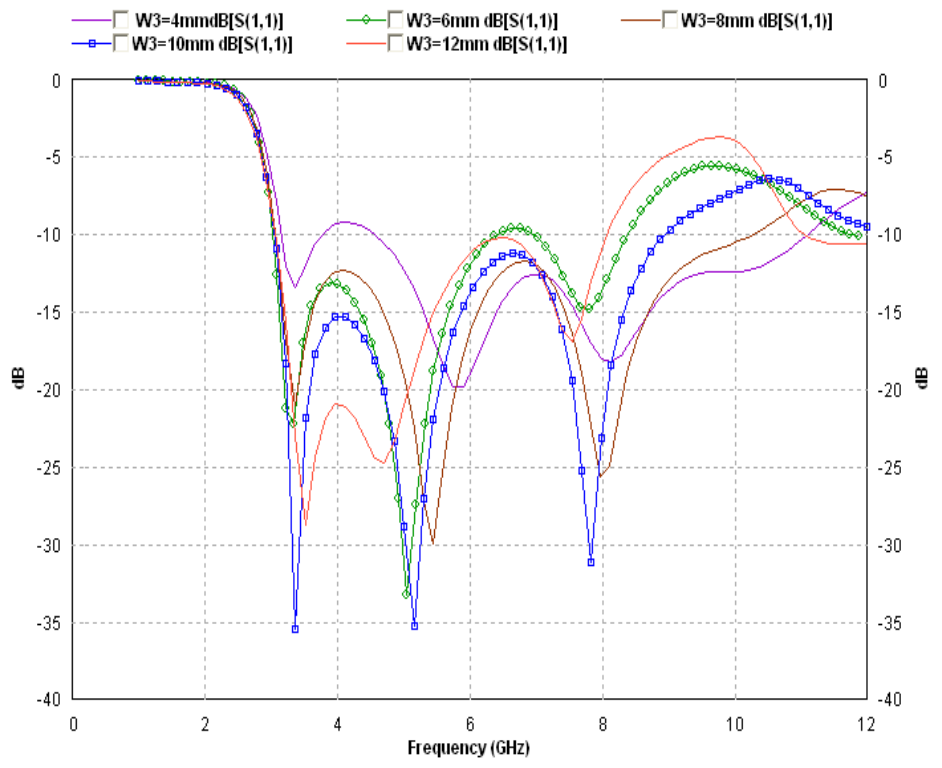

Figure 8: Simulated Return loss with different values of W3 


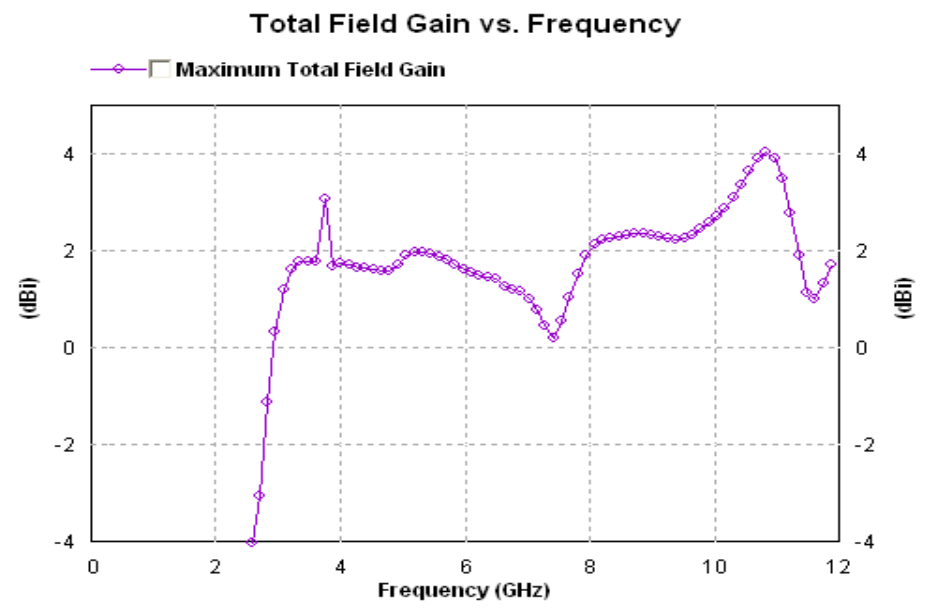

Figure 9: Proposed antenna Total Field Gain vs. Frequency

The gain of the antenna is observed in Figure 9. Here we can see the gain of the antenna is $1.75 \mathrm{dBi}$ and $1.9 \mathrm{dBi}$ at resonant frequencies $3.36 \mathrm{GHz}$ and $5.58 \mathrm{GHz}$.

\section{Discussion}

From the above figures we can observe that the gain and return loss and VSWR and impedance matching of the antenna as good as compared to reference papers So this antenna is suitable for Ultra Wideband Applications because it covers the frequency range $3.1 \mathrm{GHz}$ to $10.6 \mathrm{GHz}$. The size of the antenna is also very less compared to reference papers.

\section{Conclusion}

In this paper a novel compact CPW-fed antenna is proposed for ULTRA WIDEBAND applications. The return loss and VSWR and gain, Bandwidth are all meets of the acceptable antenna standards. The proposed antenna has a simple and effective feeding structure has adequate operational bandwidth, and has radiation patterns such that it is suitable for use in ULTRA WIDEBAND applications. Here the gain and bandwidth of the antenna are in very good promising condition so advantages of these antenna are easy to construct, simple structure, and low cost.

\section{References}

[1] First Report and Order (FCC 02-48). Action by the Commission February 14, 2002.New Public Safety Applications and Broadband internet access among uses envisioned by FCC authorization of Ultra-Wideband Technology

[2] S. Belrose. The Sounds of a Spark Transmitter: Telegraphy and Telephony. Adventures in CyberSound.

[3] Dr. Robert J. Fontana. A Brief History of UWB Communications. Multispectrum Solutions, Inc.

[4] V. H. Rumsey, "Frequency Independent Antennas," 1957 IRE National Convention Record, pt. 1, pp. 114-118.

[5] J.D. Dyson, "The Unidirectional Equiangular Spiral Antenna," IRE Trans. Antennas Propagat., Vol. AP-7, pp. 329-334, October 1959

[6] Ross, G.F., 1968, A time domain criterion for the design of wideband radiating elements, IEEE Trans. Antennas Propagat., Vol. 16, No. 3 , p. 355 .

[7] Dr. Tarance W. Barrett. History of Ultra Wideband (UWB) Radar \& Communications: Pioneers and Innovators

[8] IEEE Transactions on Antennas and Propagation, Vols. AP-17, No. 3, May 1969; Vol. AP-22, No. 1, January 1974; and Vol. AP31, No. 6, Part II, November 1983.

[9] G. M. Zhang, J. S. Hong, B. Z. Wang, Q. Y. Qin, J. B Mo, andD. M. Wan, "A novel multi folded UWB antenna fed by CPW,"J. of Electromagn.Waves and Appl., Vol. 21, No. 14, pp. 2109-2119, 2007.

[10] Saou-wen Su, and Kin-Lu Wang, "Printed band-notched ultra wideband quasi-dipole antenna," Microw. Opt. Technol. Lett., vol. 48, No 3, pp. 418-420, March 2006.

[11] X. Qing, and Z. N. Chen, "Compact coplanar waveguide-fed ultra-wideband monopole-like slot antenna," IET, Microwave, Antennas and Propagation, vol.3, no.5, pp. 889-898, August, 2009.

[12] Shyh-Kang Jeng, Ming-Iu Lai, "Slot Antennas with an Extended Ground for Multiple-Antenna Systems in Compact Wireless Devices" IEEE Antennas Wireless propagates, Lett, VOL. 8, 2007.

[13] T. G. Ma and S. K Jeng, - Planar miniatured-slot-fed annular slot antennas for ultra-wideband radios, $\square$ IEEE trans. Antennas Propag., vol.53, pp. 1194-1202, Mar. 2005

[14] Y. Gao, B. L. Ooi, and A. P Popov, -Band notched ultra wide band ring monopole antenna, $\square \quad$ Microw. Opt. Technol. Lett., vol. 48,No. 1, pp. 125-126, Jan 2006.

[15] Zeland Software, Inc., IE3D. 